\title{
La densidad genérica y la novela del ochocientos: Los pazos de Ulloa de Emilia Pardo Bazán
}

\author{
GERMÁN GULLÓN \\ Universidad de Pennsylvania \\ La expresión poética es un pensamiento que \\ emplea tropos. No se trata de señalar cosas \\ sino de expandir la imaginación por medio de \\ metáforas y metonimias, de parábolas y \\ alegorias. \\ Daniel Bell, Guttemberg y la computadora
}

La novela constituye, en palabras de José Ortega y Gasset, un género tupido ${ }^{1}$. La novela moderna, de acuerdo con las ideas del pensador español, se caracteriza por hallarse repleta de intuiciones, comentarios, observaciones (y visiones) profundas de la voz que cuenta. Aplicando tales juicios a la ficción realista-naturalista española, clave para entender la modernización del género, observamos en seguida una diferencia entre la narrativa de la década de los ochenta y la producida entre los años 1850-1870 por Rosalía de Castro, Fernán Caballero o Pedro Antonio de Alarcón, por citar tres nombres representativos, consistente en que la narrativa naturalista alcanzó una plenitud expresiva ausente de las corrientes novelísticas precedentes. Debido, entre otros factores, a que sus componentes narrativos lograron equipararse en im-

Ortega y Gasset dedicó a este tema una sección de su estudio Ideas sobre la novela (1924), la titulada, «La novela, género tupido»; aparece en el volumen Meditaciones del Quijote, 8. ${ }^{\mathrm{a}}$ edición, Madrid, Revista de Occidente, 1970 , pp. 193-196. 
portancia y efectividad comunicativa con los novelescos, en fin, a que en ella se narra más y se cuenta menos. El texto se convirtió en la envoltura esencial de lo contado, mientras la historia novelesca se presentaba conscientemente interrelacionada con la acción discursiva.

Retomando la imagen orteguiana proveniente de las ciencias naturales, diré que es como si la novela de los años ochenta del siglo pasado hubiese sido injertada con innovadoras posibilidades narrativas que, sumadas a las tradicionales, las que basaban su novedad en la manipulación de la trama de ficción, confirieron al género una mayor frondosidad. Si consideramos la evolución novelística en la obra de Benito Pérez Gáldós, comprobaremos lo aducido sin dificultad. Es fácil podar el entramado narrativo de sus novelas de tesis, condensarlo en un esquema accional; menos sencillo resulta reducir la acción de cualquiera de sus novelas contemporáneas a los constituyentes esenciales, puesto que quien la cuenta se vale, entre otros varios recursos, de una ironía muy sutil, y, a veces, de la ambigüedad. El esfuerzo compositivo no recae ahora sobre la trama, ni se pretende tampoco producir una superior complicación de la intriga mediante el entrecruzamiento de las líneas de progreso argumental, cuyo propósito solía sorprender al lector con acontecimientos inéditos. A partir de La desheredada (1881), el avance argumental se ve subsumido por la complejidad mental de los personajes, de la situación, y de la voz que los crea; Clarín ya señaló y ensalzó la novedad que en este sentido entrañaba el hacer galdosiano, a la par que la crítica en general lo condenaba. Lo que pretendo indicar es que además de los rasgos naturalistas observables en la ficción, la entrada del naturalismo en la narrativa nacional coincide con una transformación genérica, cuando la ficción se hace tupida. Tanto La desheredada como La Regenta o Los pazos de Ulloa evidencian sobradamente la caracterización señalada.

Se observará que apenas rozo el naturalismo, y me salgo por la tangente. Digo que ciertas novelas de Galdós, o de Alas, y Los pazos de la Pardo Bazán son naturalistas, y, acto seguido, alego algo distinto, su pertenencia a un género denso. Alguien podría atajar mis disquisiciones aduciendo que la frondosidad proviene de una convergencia de influencias, las provenientes de la novela psicológica, particularmente de la novela rusa, y de la naturalista. Explicación muy plausible, si consideramos la cuestión desde la tradicional mira historiográfica. Mas mi propósito es efectuar una explicación inductiva de Los pazos observando la novela como es, no como llegó a ser concebida en los términos 
en que hoy la leemos. Sin prescindir de lo mucho y bueno que sobre a obra se ha escrito ${ }^{2}$-empresa imposible, por otro lado-, quisiera describirla de acuerdo con parámetros genéricos y no histórico-literarios.

La cuestión del espesor de la novela latía ya en los escritos teóricos de la pasada centuria, e incluso los términos con que a ella se alude resultan bastante actuales. Leamos un par de testimonios con el fin de comenzar nuestra argumentación. Comentando Fortunata y Jacinta (1886-1887), Marcelino Menéndez y Pelayo dijo que en sus páginas «la vida [es] tan densa, tan profunda a veces la observación moral, tan ingeniosa y amena la psicología, o como quiera llamarse aquel entrar y salir por los subterráneos del alma [que] caben [en la novela] todas las transformaciones morales y materiales de Madrid desde 1868 a 1873 (p. $102)^{3}$. A esa densidad indicada por el crítico montañés añadiría Clarín otra característica relevante para mi propósito actual, cuando observó, refiriéndose a $L a$ desheredada, que:

La novela, si quiere ser imitación de la vida real, en lo que convenimos todos, necesita no tener esos artificiosos nudos y desenlaces [...] en el mundo, del choque y enlace de los sucesos, de las pasiones y cuanto influye en la vida no nacen dramas bien compuestos, ni novelas acabadas y cerradas so-

2 Pienso en la multitud de libros que han ido formando las opiniones críticas de sucesivas generaciones de hispanistas sobre la narrativa de doña Emilia: Donal F. Brown, The Catholic Naturalism of Pardo Bazán, Chapel Hill, The University of North Carolina Press, 1957; Sherman H. Eoff, The Modern Spanish Novel, New York, New York University Press, 1961, traducido al castellano en 1965, Barcelona, Seix Barral; Robert E. Osborne, Emilia Pardo Bazán. Su vida y sus obras, México, De Andrea, 1964; Walter T. Pattison, Emilia Pardo Bazán, New York, Twayne, 1971; Nelly Clémessy, Emilia Pardo Bazán romancière (La critique, la théorie, la practique), 2 vols., Paris, Centre de Recherches Hispaniques, 1973, traducido al español en 1891, Madrid, Fundación Universitaria Española; Benito Varela Jácome, Estructuras novelísticas de Emilia Pardo Bazán, Santiago de Compostela, Cuadernos de Estudios Gallegos, 1973; Mercedes Etreros, María Isabel Montesinos y Leonardo Romero, Estudios sobre la novela española, Madrid, Consejo Superior de Investigaciones Científicas, 1977, especialmente las pp. 49-131; Maurice Hemingway, Emilia Pardo Bazán: The Making of a Novelist, Cambridge, Cambridge University Press, 1983; Mariano López-Sanz, Naturalismo y espiritualismo en la novela de Galdós y Pardo Bazán, Madrid, Pliegos, 1985. Muchos otros especialistas como Mariano Baquero Goyanes, Gilberto Paolini, Harry Kirby, Carlos Feal Deibe o Dario Villanueva han contribuido significativamente al estudio de nuestra autora, y las referencias bibliográficas de algunos de ellos aparecerán en el texto o en las notas subsiguientes.

3 Cito por Discursos, Madrid, Espasa-Calpe, 1956. El texto citado es el discurso de contestación al de don Benito Pérez Galdós, pronunciado por don Marcelino el día 7 de febrero de 1897. La paginación de esta cita, como a todas las del estudio, va incluida en el cuerpo del trabajo. 
bre sí mismas [...] si se quiere comprender que la verdad de la narración exige no poner puertas al campo, ni desfigurar la trama de la vida con engañosas combinaciones de sucesos simétricos, de felices casualidades...» (p. 237) ${ }^{4}$.

Así pues, Menéndez Pelayo advirtió la solidez de la obra maestra galdosiana, su grosor físico y psicológico, a la par que Leopoldo Alas se fijaba en la pluralidad accional, en cómo Galdós había descartado la narración lineal por artificiosa. Percibieron ambos que el espejo realista se iba haciendo más cóncavo, que el género se aprestaba, a modo de vientre, a acoger una realidad que no es que ofreciera mayor complejidad que la precedente; lo que había variado era su entendimiento. Y esto requería que la novela diese un paso gigante, abriendo sus entrañas para que la multiplicidad de impresiones de lo mental, de lo fisiológico y de lo social vinieran a habitar la casa de la ficción. Esto exigía que se derribasen paredes, se rediseñasen sus espacios y se modificase el horario por el que se regían los personajes, quienes, a su vez, se multiplicaban en número, mientras sus maneras de hablar se iban diversificando; en resumen, la novela se regeneraba para dar cabida a una visión distinta de la realidad.

Venimos a comprobar, con los testimonios de Menéndez Pelayo y de Alas, que en el propio siglo XIX se entendieron las variantes genéricas introducidas en la década de los ochenta, cuando la voz narrativa comenzaba a complicarse, rompiendo las costuras tradicionales del género. La pretensión de arbitrar si la novela es objetiva o no, de si siguió los dicta zolescos o no, como muchos lo hemos intentado, supone considerar la cuestión palpitante a medias. La evidencia, de acuerdo con mi interpretación, apunta a la existencia de aspectos distintos del impacto producido por el naturalismo en la novela española; entre otros, el de la conformación de una novela donde reina la pluralidad intuitiva.

Parece indiscutible que el estilo de ficción de la época se vio marcado por el empleo de un léxico fisiológico, por las ideas referentes al medio social, a la herencia, etc. No obstante, conviene que en el momento presente saquemos del purgatorio (el encasillamiento en ismos forjados en los berroqueños cánones historiográficos) la novela naturalista española, estudiando junto a las marcas externas, visibles, o a las cuestiones filosóficas subyacentes, la profunda metamorfosis del género cuando a la prioridad concedida a la observación por el realismo

4 Tomo la referencia del libro editado por Sergio Beser, titulado Leopoldo Alas: Teoría y crítica de la novela española, Barcelona, Laia, 1972. 
se le une la percepción múltiple propia del naturalismo (del realismo naturalista). Entonces la novela deja de adscribir a los personajes características inmutables, haciéndolas cambiantes; la trama deja de ser el centro de atención, volviéndose a explorar las variantes que la percepción psicológica ofrece al artista. La novela idealista de Juan Valera, su Pepita Jiménez (1874), exhibía ya rasgos del nuevo psicologismo; sin embargo, la búsqueda por parte del autor de un final redondo (lazo matrimonial) que aunase todo lo transcurrido, sacrifica en aras de la visión única cualquier posible desarrollo menos convencional. El naturalismo, al abrir las puertas de la novela a un psicologismo amplio, freudiano, si se me permite esta forma taquigráfica de aludir al fenómeno que intento circunscribir, oscurece, complicándolo, el trasfondo de toda creación novelesca. La conducta de los personajes comenzará a responder a móviles impensables en la novela anterior; escapan a la lógica retórica, a la poética novelística del idealismo, de la ficción romántica en general; pienso, por ejemplo, en la escena, que luego comentaré, en que Julián, cura inocente y santurrón, siente la cercanía carnal de Sabel. Tal mezcla de emociones, la santidad y la excitación sexual, no solía caber dentro de la misma sensibilidad en la novela pre-naturalista, excepto en los casos en que tal dualidad de emociones venía dramatizada.

Cuando consideramos Los pazos de Ulloa dentro de la secuencia de la historia de la novela española, una de las primeras cosas que notamos es la desaparición de la facultad imaginativa como motivadora de las acciones de los personajes. «La loca de la casa» ha sido relegada como motor principal de la conducta humana, el narrador busca las claves de la conducta en elementos distintos, el medio, la físiología, etc. Lo cual supone una ampliación del espectro genérico; se produce una re-contextualización del ser de ficción. La Historia facilita el trasfondo temporal: la época de la Revolución de 1868 . El medio, en que la naturaleza y la civilización se disputan el predominio sobre la conducta personal, proporciona el entorno, mientras la narración discurre por los caminos de la indagación psicológica. El estilo indirecto, el diálogo y el monólogo interior proveen las técnicas apropiadas para examinar la motivación de los actos humanos.

Existe además en Los pazos todo un plano de realidad suprasensible, compuesto por los roces (p. 194) ${ }^{5}$, los rumores (p. 194), los sue-

5 El texto de la novela lo cito siempre por el que aparece en las Obras Completas, Madrid, Aguilar, 1957. 
ños (p. 241), ventanas que crujen y que quizás sean «almas del otro mundo que se quejan» (p. 243), «brujas sueltas» (p. 246), conciencias que leen en las cartas el porvenir de los personajes, etc. Componente que sirve para encantar la realidad, al imponer una naturaleza menos determinista, envuelta en un aura de misterio.

Por tanto, si consideramos ambos planos de la realidad textual, el verosímil y el suprasensible, la imagen de Los pazos revela una sobrefiguración de ciertos elementos de la obra, la presencia de la Historia, el lenguaje fisiológico - «intestinos», «personas linfáticas», «región sacrofílica»-, la solidez de ciertas circunstancias novelescas, como la presencia de Perucho, testimonio de la realidad de la obra, frente a la indeterminación de lo misterioso. No podemos menos de reconocer en el texto una textura especial, de claras figuras en el frente y de oscuridad y misterio al fondo. Ésta sería la primera prueba de lo tupido que es el conjunto, pues se están así mezclando puntos de diferente hilado. $\mathrm{O}$ dicho de forma distinta, el texto de la Pardo Bazán produce, gracias a tal mezcla, una visión novelística con profundidad (trasfondo): desde la superficie textual de la trama, donde se destacan las figuras novelescas en pose accional, pasamos a través de las sombras proyectadas por las motivaciones de oscura procedencia, los sucesos extraños, a sumirnos en la densidad de un mundo reviviscente. La conducta que, en un principio, es explicable, poco a poco pierde su poder de convicción para sumirnos en lo ambiguo de su complejidad.

Hay otro aspecto de la narración que contribuye a incrementar las reverberaciones de lo incorrecto en el conjunto textual. Parece evidente que el narrador actúa de traductor en gran parte de la novela, ya que varios de sus pobladores hablan «en dialecto» (p. 168), y sólo en contadas ocasiones les oímos expresarse en el idioma gallego. En el breve pasaje donde Perucho le cuenta a su hermana un cuento, observamos al narrador incorporando al gallego la correspondiente traducción castellana: «Este rey tenía una nené bunita, bunita, como la flol de mayo... y pequeñita, pequeñita, como un grano de millo - maíz, quería decir Perucho« «(279). Sin dejar de notar que el galleguismo en las líneas citadas sólo afecta al léxico, cuando en realidad debería afectar por igual a la sintaxis, a la dicción y demás, el hecho es que la lengua gallega, especialmente en su variedad rural, late en el núcleo narrativo de la obra. Una lengua transida de expresiones folklóricas, del folklore del noroeste, con sus supersticiones y alusiones infrecuentes en el habla castellana. O sea, que el empleo del castellano por parte del narrador, y recuer- 
do de nuevo el léxico fisiológico que utiliza, es otra manera de superfigurar la realidad novelesca, que estiliza una realidad subyacente con connotaciones y mecanismos perceptivos distintos.

La realidad textual encierra, sin duda, una complejidad imposible de explicar por medio de las relaciones de causa y efecto, mediante las que habitualmente justificamos el progreso de la trama novelesca. Casi me atrevería a decir que el encadenamiento de los ¿por qués? con que construimos la trama de una novela, cuando queremos contársela a otro, resulta ahora una explicación insuficiente. Por qué suceden las cosas en Los pazos nos deja siempre más acá de lo ocurrido en la novela que un estudio de cómo pasan y de la manera en que se cuentan. Para entender bien estos últimos hay que efectuar una lectura textual conjuntamente con la novelesca.

\section{La textura psicológica}

La apertura de Los pazos de Ulloa supone un acercamiento de dos mundos, el cuasi-legendario, rural, y el civilizado, tal y según lo encarna Julián Álvarez. Apropiadamente comienza la novela con el viaje del recién ordenado por los agrestes caminos que conducen a las tierras del Señor de Ulloa, adonde se dirige para tomar posesión de la capellanía de la casa solariega. Jornada que para él supone un viaje laberíntico ${ }^{6}$, debido a la imprecisión y parquedad de las direcciones a su disposición. «¿Cuánto falta?», pregunta Julián a un peón: «-Un bocadito, un bocadito...» (p. 169). Una labradora responderá a la misma pregunta con la expresiva frase: «La carrerita de un can...» (p. 168). Los hitos del camino tampoco orientan demasiado; al contrario, resultan ominosos: «Una cruz de madera, pintada de negro con filetes blancos, medio caída ya sobre el murallón que la sustentaba. El clérigo sabía que estas cruces señalaban el lugar donde un hombre pereció de muerte violenta» (p. 168). Por fin, encuentra a unos guías de confianza, al Señor de los Pazos acompañado por Primitivo y el Abad de Ulloa; le indicarán la forma de proseguir la marcha, sumiéndole en un laberinto aún mayor, el mundo de los pazos, donde nunca logrará hallar el hilo de Ariadna.

6 Darío Villanueva en su importante ensayo «Los pazos de Ulloa, el naturalismo y Henry James», aparecido en Hispanic Review, 52. Núm. 2, 1984, habla ya de «El laberíntico camino hacia la experiencia de la vida [de Julián]...» (p. 127). 
La llegada a los pazos propiamente dichos le introduce en otro enredo. Cuando por «varios corredores sombríos» llega finalmente a la «espaciosa cocina», encuentra otra naturaleza igualmente desconocida para él. Entrevé a «un rapazuelo de tres o cuatro años» (p. 171) disputando unos pedazos de carne a los perros de caza; acto seguido, asiste escandalizado al emborrachamiento del chiquillo, Perucho. La intención de la Pardo Bazán parece evidente, servirse de Julián para mostrar que la visión civilizada del mundo vegetal, animal, y humano, padece severa miopía; sólo cuando contemplemos el mundo de cerca distinguiremos sus verdaderos perfiles, tras abandonar el código distanciador del idealismo. Veamos con detalle un ejemplo de aproximación, cuando Julián, acabado de levantarse, contempla la Naturaleza desde la ventana de su habitación:

Lo que abarcaba su vista le dejó encantado. El valle ascendía en suave pendiente, extendiendo ante los pazos toda la lozanía de su ladera más feraz. Viñas, castañares, campos de maíz granados o ya segados y tupidas robledas se escalonaban, subían trepando hasta un montecillo, cuya falda gris parecía, al sol, de un blanco plomizo. Al pie mismo de la torre, el huerto de los pazos asemejaba verde alfombra con cenfas amarillentas, en cuyo centro se engastaba la luna de un gran espejo, que no era sino la superficie del estanque. (p. 175)

Entonces, Julián siente unas pisadas, «y al volverse vio a Sabel, que le presentaba con una mano platillo y jícara, y con la otra, en plato de peltre, un púlpito de agua fresca y una servilleta gorda...» (p. 175). Nota que «la moza [venía] arremangada hasta el codo, con el pelo alborotado, seco y volandero, del calor de la cama, sin duda; y a la luz del día se notaba más la frescura de su tez, muy blanca y como infiltrada de sangre» (p. 175). La luna del estanque se ha reducido, por medio de la aproximación narrativa, a un «púlpito de agua fresca», que le ofrece la lozana Sabel. Su pudor se revuelve, la proximidad de la moza le ha producido una sensación nueva, y la conmina: «-Otra vez haga el favor de dar dos golpes en la puerta antes de entrar... Conforme estoy levantado, pudo cuadrar que estuviese en la cama todavía..., o vistiéndome» (p. 175). A la distancia, la naturaleza es un bello marco, perfecto para acoger la visión idealista; la redonda luna acostándose en el estanque supone una invitación a perdernos en las brumas de lo inconsciente, en la tranquilidad del agua en calma, en la contemplación inactiva, mientras el púlpito de agua, sostenido por las manos de la gallarda moza, simboliza el agua en su frescor, le incita con sus posibilidades vitalizadoras. Eso es lo que siente Julián, los peligros de una naturaleza 
viva, las turgencias y formas de la muchacha provocando en él una reacción, e instintivamente la rechaza, para imponer distancia. Se da cuenta de que la naturaleza no es sólo objeto de contemplación, vista desde el civilizado marco de una ventana, sino que cuando la sentimos despojada del ideal, late en ella la provocación, suscitadora del deseo de acercarnos a calmar la sed.

La novela así concebida revela una serie continua de aproximaciones / distanciamientos. Julián querrá que don Pedro se acerque a la civilización, por ello le anima a viajar a Santiago en busca de una cónyuge apropiada. Una vez allí, el juego de las aproximaciones lleva a don Pedro hacia Rita, la exuberante primita, mas el Marqués se aleja de ella, casándose, en cambio, con Nucha, la joven bizca, quien vive lamentando la ausencia de su hermano Gabriel, estudiante en el Academia de Artillería, a quien ella había criado. De regreso en los pazos, don Pedro atiende a la esposa con cariño, hasta que da a luz a una niña, circunstancia que lo aleja definitivamente, desilusionado por el sexo de la heredera, y le devuelve a los brazos de la concubina. Quienes no podrán separarse de Manuela, la recién nacida, son Perucho, el hijo ilegítimo de Sabel y el Marqués, y Julián.

Junto a la distancia psicológica que separa a don Pedro, a Primitivo y al Abad, de Nucha y de Julián, tenemos también la física, no sólo de don Pedro y Nucha, sino de Julián y Nucha, quienes no pueden verse cuando ella cae enferma. El acecho de Primitivo es una constante de esos acercamientos y alejamientos; él vigila que nadie salga ni entre de los pazos sin su conocimiento.

Una aproximación importante es la narrada en el capítulo XIX ${ }^{7}$, cuando una vieja, la Sabia, echa las cartas a Sabel, y mediante su lectura descubrimos lo presentido: que Julián ama a Nucha, aunque éste sea incapaz de reconocerlo en su consciente, donde se halla distanciado de su amada. El cariño habido entre Manuela y Perucho supone un ejemplo parecido de máxima aproximación, por amor, y de alejamiento en que los coloca su situación familiar, por ser medio hermanos sin saberlo. En el cierre de la obra ambas situaciones narrativas se enlazan. Cuando Julián regrese a los pazos tras diez años de ausencia, visitará lo pri-

7 Sobre el mismo consúltese el sugerente artículo de Carlos Feal Deibe, «Naturalismo y antinaturalismo en Los pazos de Ulloa», en el Bulletin of Hispanic Studies, 48, Núm. 4, 1971, pp. 314-327. 
mero la tumba de Nucha, donde por fin sus lágrimas delatarán su inconfesado amor. Al levantar la mirada de la tierra ve a dos niños juntos que sonríen ante el espectáculo, son Perucho y Manuela: «una pareja hechicera» (p. 283). Cuando Julián se siente, por fin, cercano a su Nucha, gracias a la lejanía que impone la muerte, es cuando descubre a los niños unidos, en cercanía imposible. El laberinto exhibe una puerta de salida infranqueable, parecida a la que imposibilitaba su unión con Nucha; sin embargo, la parejita, inconsciente del riesgo, cruzará su umbral: el incesto acontecerá en la novela siguiente, La madre naturaleza (1887).

Las aproximaciones / distanciamientos comentados desempeñan la función de tupir la trama de la novela, haciendo que la naturaleza y la civilización se enlacen mientras se separan. La obra no avanza linealmente, las aproximaciones / distanciamientos entrecruzan las acciones; no asistimos al choque de la naturaleza y la civilización, sino a la aclimatación del personaje a un medio distinto, donde lo imaginativamente impensable se produce, el emparejamiento de Perucho y Manuela. La trama novelesca del XIX gana, por tanto, en flexibilidad, convirtiéndose en una red suceptible de acoger la multiplicidad de encuentros y desencuentros producidos en la realidad. Las digresiones imaginativas predominantes en la novela de los cincuenta se ven sobreseídas en favor de una progresión novelística donde la acción, además de una suma de porqués, supone la exploración de una multiplicidad de cómos. De cómo la vida se vuelve sobre sí misma, en ese salto que llamamos el azar o el destino, asignándonos una situación social y un status económico, o nos dota de una herencia que nos confiere la complexión física.

En suma, el existir novelesco duplica la inestabilidad del vivir. Antes mencioné La Regenta junto a Los pazos, y dije que se asemejaban por su naturalismo, es decir, y según voy definiendo aquí el ismo, por su pertenencia a la modalidad tupida del género. Lo que las diferencia es que el asturiano hará que sea la opinión, el qué dirán, la mojigatería, la superficialidad de juicio, los que avasallen a los personajes sensibles que habitan Vetusta, mientras los pazos de Ulloa son como un «oscuro pozo» (p. 264), el lugar donde se ven sumidos los personajes, y allí resulta difícil distinguir cuáles sean las motivaciones de la conducta. Es la redondez del catalejo de don Fermín, mirando desde la catedral a Ana Ozores, la imagen visual, con lo que conlleva de penetración viciosa en la intimidad personal, lo que define la novela de Clarín, mientras es la 
circularidad de las húmedas y ruinosas paredes del pazo-pozo lo que define la situación de sus habitantes.

Nos da pie tal contraste para continuar nuestro asedio a Los pazos. El texto de la Pardo, desde un punto de vista puramente técnico, es desigual; en una comparación de ese aspecto con La Regenta o Su único hijo, Alas saldría ganador. Basta pensar en el episodio en el que Perucho, oculto tras la puerta de la capilla, escucha las confidencias de Nucha a Julián, cuando ella confía al capellán el deseo de huir de los pazos. El niño corre a contarle a su abuelo, Primitivo, que la señorita y el cura hablan a solas en la iglesia, lo cual le vale unos cuartos del viejo. Estas instalaciones de tercería narrativa, de celestinismo, resultan inapropiadas, según he estudiado en otro lugar ${ }^{8}$; revelan un cierto apresuramiento en la composición, exhalan un tufillo folletinesco, al tiempo que revelan una cierta pereza narrativa, puesto que tales procedimientos ahorran al autor el trabajo de presentación de lo ocurrido con mayor verosimilitud. Ahora, la complejidad narrativa conseguida por Alas, gracias en parte a su habilidad, a su destreza a la hora de componer un texto polifónico, compuesto a varias voces perfectamente sincronizadas, la consigue doña Emilia por otros medios, a través del dominio de los mecanismos del empleo del lenguaje realistanaturalista, que en sus mejores momentos me parece insuperable.

\section{El tejido metonímico}

Antes de proseguir, puntualizaré todavía alguna de mis observaciones respecto a las técnicas narrativas; me refiero a lo que apunté unas páginas antes sobre la baja rentabilidad del rastreo de las huellas dejadas por el objetivismo narrativo, propuesto por la teoría de Zola, en los textos de doña Emilia. Necesitamos, de entrada, salvar el obstáculo terminológico; los críticos actuales tendemos, al hablar del tema, a usar un referente distinto del que poseían la Pardo Bazán o el mismo Zola. El nuestro suele provenir de la poética del nouveau roman, el intento más decidido en la historia literaria europea de lograr la objetividad narrativa. La Pardo escribía en un contexto distinto; su objetivismo, a mi

8 Me refiero a mi artículo, «Narrativizando la Historia: La Corte de Carlos IV», Anales Galdosianos, 19, 1984, pp. 45-52. 
parecer, se relaciona con la inclusión de la mayor cantidad de datos, lo que llamé amplitud de espectro, con la superación del exclusivismo de lo racional y de lo imaginatvo, incluyendo lo social, lo psicológico, etc. Es decir, la escritora gallega no buscaba la objetividad a través de la consistencia del punto de vista (en puridad imposible de lograr) de las técnicas narrativas, sino que pretendía incluir en la novela cuantos datos creía pertinentes para lograr una mejor inteligibilidad del texto.

Es impensable que doña Emilia fuera simplemente una descuidada a la hora de narrar, insconsciente del hecho de que ciertas transiciones entre episodios parecen demasiado abruptas: que pasemos de un momento en que se habla del ambiente chismoso del casino, y casi sin aviso, veamos a don Pedro casado y camino de los Pazos (p. 215). Tampoco presta mayor atención a la textura narrativa, haciendo que el narrador unas veces sea omnisciente y otras se valga sin mayor reparo de formas de narración indirecta.

Donde se revela su esfuerzo narrativo es en la creación del lenguaje, en el nivel de la expresión. Allí es donde luce su maestría. Varios críticos han comentado ya su agudeza y la enorme riqueza estilística de doña Emilia; recuerdo ahora los comentarios de Carlos Feal al capítulo XIX de la obra, o los de Maurice Hemingway a la descripción de Julián al comienzo de la obra. $Y$ en la veta abierta por ellos y otros comentadores del estilo de la escritora gallega, quisiera yo seguir minando ahora.

Aludí previamente al hecho de que los creadores de novelas tupidas atribuyen una importancia secundaria al desarrollo de la trama lineal, afirmando que predominaba en ese tipo de libro la percepción múltiple de lo contado. Desearía en este momento sustanciar esa característica diferencial que le atribuyo a la novela de los años ochenta, y centrándome en el texto pardobazaniano, analizar la diferencia existente entre el lenguaje de los personajes y el del narrador. Entrando sin mayor preámbulo en la cuestión, diré que el discurso del narrador aparece salpicado de expresiones metonímicas, que contrastan a cada paso con las deformaciones metafóricas, ilusiones idealistas, incluso melodramáticas, de los seres ficticios, que se incrustan en su discurso a través de diálogos, monólogos interiores, o simple recuento de lo que aquéllos piensan. Repito, el discurso del narrador ${ }^{9}$. Se trata, por tanto de un

9 Confirma mi opinión Darío Villanueva, en art. cit. cuando dice: «Siempre [en Los pazos] habla el narrador... (p. 130). 
discurso donde se produce un choque de dos maneras verbales de colorear el mundo al que se enfrentan los personajes, en cuya percepción participa también el narrador. Examinemos un ejemplo, cuando Nucha se halla sola por primera vez esperando a su recién desposado, don Pedro Moscoso. Dice así:

Parecíale que aquella habitación donde reinaba tan imponente silencio, donde ardían tan altas y graves las luces, era el mismo templo en que no hacía dos horas aún se había puesto de hinojos... Volvió a arrodillarse, divisando allá en la sombra de la cabecera del lecho el antiguo Cristo de ébano y marfil, a quien el cortinaje formaba severo dosel. Sus labios murmuraban el consuetudinario rezo nocturno: «Un padrenuestro por el alma de mamá...» Oyéronse en el corredor pisadas recias, crujir de botas flamantes, y la puerta se abrió (pp. 210-211).

Las palabras «templo», «hinojos», «Cristo de ébano y marfil», «rezo», y las actitudes que las acompañan, más el asemejar la habitación matrimonial a la capilla de los esponsales y del sacrificio de la misa, revelan la confundida visión místico-religiosa de la pobre Marcelina con respecto a la noche de bodas. A continuación, las metonimias, «las pisadas recias, [e1] crujir de botas flamantes» (p. 211) anuncian la verdad del sacrificio; el vigoroso andar de Moscoso anuncia el contacto físico, preludiando el temor que asaltará a la novicia ante el tálamo matrimonial. Tenemos, pues, dos discursos enfrentados, el metafórico, manifiesto en el acercamiento entre la habitación y el templo, y el metonímico; el crujido del piso al andar es una mera parte de la contundencia de hábitos en el trato del Señor de los Pazos. El texto del narrador constituye una especie de sobrehilado que tupe los huecos dejados por el lenguaje metafórico de los personajes; el narrador hace que la situación novelesca resuene en la situación textual, le añada densidad, haciéndola más figurativa. Trae al consciente del texto todo un substrato de conciencia que no aflora por sí misma a la superficie de la conciencia de los personajes, a la que da relieve o, dicho de otra manera, el narrador enfoca la narración según cauces figurativos que vitalizan el lenguaje metafórico.

El narrador exhibe constantemente su conciencia de la inadecuación del lenguaje de los personajes para concebir el mundo en términos realistas. Citemos un par de ejemplos:

En materia de desnudeces infantiles, Julián no era voto, pues sólo conocía las de los angelotes de los retablos; pero cavilaba para sus adentros que, a pesar de haber el pecado original corrompido toda la carne, aquella que le estaban enseñando era la cosa más pura y santa del mundo: un lirio, una azucena de candor (p. 236). 
En Nucha, el espectáculo producía las hondas impresiones de la luna de miel maternal, exaltadas por un temperamento nervioso y una sensibilidad ya enfermiza. A aquel bollo blando, que aún parecía conservar la inconsistencia del gelatinoso protoplasma, que aún no tenía conciencia de sí propio ni vivía más que para la sensación, la madre le atribuía sentido y presencia, le insuflaba en locos besos su alma propia, y en su concepto de chiquilla lo entendía todo, y sabía y ejecutaba mil cosas oportunísimas y hasta se mofaba discretamente, a su manera, de los dichos y hechos del ama. «Delirios impuestos por la Naturaleza con muy sabios fines», explicaba Juncal. ¡Qué fué el primer día en que una sonrisa borró la grave y cómica seriedad de la diminuta cara y entreabrió con celeste expresión el estrecho filete de los labios! No era posible dejar de recordar el tan traído como llevado símil de la luz de la aurora disipando las tinieblas. La madre pensó chochear de alegría (pp. 236-237).

Es de notar, como dije, la conciencia del narrador con respecto al lenguaje. Al penetrar en la mente de los personajes para allí pulsar su manera de pensar, descubre la idealidad de sus reacciones, su total alienación de la realidad. El niño es descrito por Julián como «un lirio, una azucena de candor», y su sonrisa, tal y como la siente la madre, recuerda «la luz de la aurora disipando las tinieblas». Estas metáforas sitúan la acción real en un plano ideal; suponen, en otras palabras, la creación de un contexto lírico, donde no existe ninguna relación entre causa y efecto, donde la verdad corresponde a lo deseado.

La frase final: «No era posible dejar de recordar el tan traído como llevado símil de la luz de la aurora disipando las tinieblas. La madre pensó chochear de alegría», delata la extraña vigilancia ejercida por el narrador sobre cómo Nucha es sobrecogida por los impulsos emotivos. Mas el narrador contrapuntea insistentemente su discurso con metonimias que recuerdan al lector la solidez —en el caso que a continuación cito- de lo tupido: «El capellán perfeccionaba sus nociones del arte de tener un chico en brazos sin que llore ni rabie. Consolidó su amistad con la pequeñuela un suceso que casi deberíamos pasar en silencio: cierto húmedo calorcillo que un día sintió Julián penetrar a través de los pantalones... :Qué acontecimiento! Nucha y él lo celebraron con algazara y risa» (p. 236).

El ejemplo mejor y más conocido del contraste entre lo que siente el personaje y cómo lo cuenta el narrador (entre focalización y narración) ocurre tras un sueño en que Julián se siente atravesado por la lanza de don Pedro Moscoso:

Lo sorprendente es que el lanzazo lo sentía Julián en su propio costado... Lloraba muy bajito, queriendo hablar y pedir misericordia: nadie acu- 
día en su auxilio, y la lanza le tenía ya atravesado de parte a parte... Despertó repentinamiente, resintiéndose de una punzada dolorosa en la mano derecha, sobre la cual había gravitado el peso del cuerpo todo, al acostarse del lado izquierdo, posición favorable a las pesadillas (p. 242).

El pinchazo es debido, pues, al puño que Julián tiene pillado entre su cuerpo y el colchón. Como vimos en el crujir de las pisadas, el orinarse del niño, y ahora en el puño cogido entre la cama y el cuerpo, el narrador vuelve la interpretación del revés, dándole una explicación al suceso que escapa a lo jocoso, y apunta hacia una realidad fisiológica; efectúa una figuración que se destaca en el texto, dándole un relieve distinto; es la figura que se destaca del trasfondo.

Así pues, desde el punto de vista narrativo, Los pazos se caracteriza, en vez de por su objetividad, por la constante superposición de lo metonímico sobre lo metafórico. Siendo la cadena metonímica principalmente de claros referentes físicos, queda claro que éstos conceden al texto un relieve que permite entender la novela como un contraste de dos planos narrativos, uno idealista y otro figurativo. El plano figurativo trae a la superficie textual lo que se halla implícito a lo largo de la novela, permitiendo que la audiencia lo capte por medio de las alusiones metonímicas.

El lenguaje metonímico exige que los lectores efectuemos una visualización referencial, no imaginativa, la típica del romanticismo poético de los personajes. John Crowe Ransom habló del «cuerpo del mundo»; efectivamente, el lenguaje empleado por la Pardo en Los pazos de Ulloa devuelve a la prosa de ficción ese cuerpo que la novela anterior le había escamoteado. La llena de cuerpo, la tupe; las pisadas resuenan en el corazón y en los centros sensibles de la piel, gracias a la insistencia de sobrefigurar lo físico mediante el lenguaje metonímico. Obliga a leer la novela en dos tiempos, el uno el relajado de imaginar pasivo, y el otro el verbal, donde la índole física de los referentes se impone inevitablemente.

Toda la novela realista-naturalista, la novela de los años ochenta, exhibe esta superación del plano idealista. Sea en Galdós, en su La desheredada cuando los sueños aristocráticos de Isidora Rufete se vean superados por las realidades propuestas por la situación, o bien en $L a R e-$ genta donde el amor romántico de Ana Ozores acaba siendo burlado por la realidad de la situación. Los personajes se ven atrapados en los hilos tejidos por sus deseos, por sus sueños, que el narrador va poco 
a poco deshaciendo, para rehacerlos en una realidad textual distinta. En el caso de la Pardo Bazán, la aplicación de las reglas psicológicas, de la afirmación del ser humano como un complejo fisiológico, acaba por ir deshaciendo el entramado ideal, aproximándonos al real. Por eso Los pazos de Ulloa sigue manteniendo el interés de las audiencias de ayer y de hoy: en ella asistimos a la corporeización del estilo literario. Y ésta es, junto con la dramatización, una de las características esenciales de la novela de los años ochenta de la pasada década, en los que la grandeza literaria volvió a visitar nuestras letras. 